\title{
Programa institucional de bolsa de iniciação à docência da Capes e a formação docente
}

Carlos Roberto Jamil Cury*

\begin{abstract}
Resumo
O Programa Institucional de Bolsas de Iniciação à Docência - PIBID -, objeto deste estudo, pretende, pelo conjunto dessa legislação que lhe dá consistência, dentro das competências da União, em regime de colaboração com os entes federativos, uma via de valorização do magistério da educação básica. E tal valorização se dá no momento em que estudantes da licenciatura e da pedagogia estão tendo sua formação inicial no ensino superior. $\mathrm{O}$ estudo, após uma pequena retrospectiva histórica relativa à formação docente no Brasil, mostra como a experiência exitosa da Coordenação de Apoio ao Pessoal do Ensino Superior - CAPES -, no âmbito da pós-graduação, tende a ser recontextualizada nos cursos de licenciatura e de pedagogia. O PIBID busca oferecer ao futuro licenciado um conhecimento do real em situação de trabalho, isto é, diretamente em unidades escolares dos sistemas de ensino. Para tanto, conta com o apoio institucional da entidade formadora, por meio de um orientador e com o acolhimento em estabelecimento da educação básica por um docente sênior em exercício da docência. Seus resultados mais consistentes são produtos de média e de longa duração e de outras iniciativas que sejam produto de uma política de Estado da qual decorram ações continuadas, conscientes e avaliadas.
\end{abstract}

*Doutor em Educação pela PUC/SP. Tem experiência na área de Direito à Educação, atuando principalmente nos seguintes temas: lei de diretrizes e bases política educacional legislação educacional e educação de jovens e adultos. É pesquisador do CNPq.

Palavras- Chave: Formação Docente e Formação inicial. Formação docente e Sistemas de Ensino. Programas de apoio e formação docente.

1.

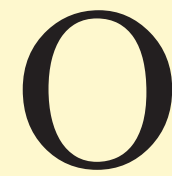
Programa Institucional de Bolsa de Iniciação à Docência - PIBID -, gerenciado pela CAPES Fundação de Aperfeiçoamento de Pessoal de Nível Superior -, veio à luz no contexto que ampliou as funções dessa agência para a educação básica pela Lei n. 11.502/07. Regulado pelo Decreto n. 7.219/2010, tem como inspiração de fundo "a garantia do padrão de qualidade" posto na Constituição de 1988, no inciso VII, do art. 206, como princípio da educação nacional. O objetivo maior desse programa é o incentivo à formação de professores para a educação básica e a elevação da qualidade da escola pública.

Pode-se ainda notar a importância dessa formação por conta da aprovação da emenda Constitucional n. 59/09 e de seus impactos sobre o Plano Nacional de Educação, cujo projeto ora encontra-se em discussão no Congresso Nacional, e sobre os sistemas de ensino. Deve-se lembrar que, até 2016, todas as pessoas entre 4 e 17 anos devem estar frequentando as escolas nas etapas próprias das idades indicadas em lei. Por fim, não se pode esquecer a lei n. 11.738/08, que institui o piso salarial profissional nacional para os profissionais do magistério público da educação básica.

O Pibid, pelo conjunto dessa legislação que Ihe dá consistência, busca, dentro das competências da União, em regime de colaboração com os entes federativos, uma via de valorização do magistério no momento em que estudantes da licenciatura e da 
pedagogia estão tendo sua formação inicial.

Essa iniciativa da União pode ser referida à sua função redistributiva e supletiva do $\$ 1^{\circ}$ do art. 210 da Constituição em que o padrão de qualidade do ensino deve contar com a devida assistência técnica e financeira para os sistemas estaduais e municipais. Mas é consequente com o art. $9^{\circ}, \S 1^{\circ}$ da LDB que dispõe caber à "União a coordenação da política nacional de educação, articulando os diferentes níveis e sistemas e exercendo função normativa, redistributiva e supletiva em relação às demais instâncias educacionais."

2.

Apesar das políticas e dos programas com descontinuidade, uma das marcas mais negativas de nossa educação, pode-se apontar algumas iniciativas que remotamente tentaram uma valorização docente.

Pode-se assinalar, na proclamação da República, a criação do Pedagogium pelo Decreto 667, de 16 de agosto de 1890 que, como instituição pedagógica modelar, manteria uma escola primária e deveria estar em dia com os avanços do conhecimento na área, com permuta de documentos, feitura de cursos, exposições, manutenção de museu pedagógico e publicação de revista. Esse instituto deveria manter relações com as instituições congêneres dos Estados.

Essa instituição representava uma presença da União na formação de docentes que até então era efetivada pelas Províncias (depois Estados) como consequência do Ato Adicional, de 1834. Desde então, por conta da descentralização, a formação de docentes para atuarem na instrução primária era responsabilidade das Províncias (depois Estados).

Essa estrutura não foi alterada com a República que aprofunda a descentralização justificada agora pelo pacto federativo e pela autonomia dos Estados. Cada unidade federada pôde criar estabelecimentos voltados para a formação docente: as escolas normais estaduais. Como não havia uma normatização nacional sobre o assunto, inexistindo um órgão central nacional para articular ou integrar as escolas normais de todo o país, é aqui que o Pedagogium representa uma oferta da União para os Estados no sentido de um aperfeiçoamento da formação docente.

Durante a chamada Velha República foram bastante eloquentes os debates em torno do papel da União em vários setores sociais entre os quais o da escolaridade no âmbito do ensino primário e da formação de docentes que nele atuariam. ${ }^{1}$ Mas os projetos de deputados e senadores não foram adiante. Entre as iniciativas parlamentares que se tornaram objeto de proposição e debates e que não chegaram a se efetivar, Constitucional de 1925-26, o que pode ser visto no discurso de Afrânio Peixoto: 
Será a fundação na Capital do Brasil, de uma escola normal superior, seminário de educação nacional, viveiro do professorado de todos os liceus e ginásios estaduais, de todas as escolas normais primárias e secundárias, espalhadas pelos 20 estados da União. Nessa escola o alcance patriótico será conseguido pela unidade pedagógica (In CURY, 2003, p. 69).

Após a Revolução de Trinta, o decreto n. 19581/31, do Ministério da Educação e Saúde Pública, outorga o Estatuto das Universidades Brasileiras cuja base seria formada pelas Faculdades de Direito, Engenharia e Medicina, havendo a possibilidade de uma delas ser substituída por uma Faculdade de Letras, Ciências e Educação.

Essa faculdade teria como objetivos específicos ampliar a cultura no domínio das ciências puras, promover e facilitar a prática de investigações originais, desenvolver e especializar conhecimentos necessários ao exercício do magistério.

A consciência da importância do magistério primário foi muito destacada no Manifesto dos Pioneiros da Educação Nova, de 1932, no qual se lê:

Todos os professores, de todos os graus, cuja preparação geral se adquirirá nos estabelecimentos de ensino secundário, devem, no entanto, formar o seu espírito pedagógico, conjuntamente, nos cursos universitários, em faculdades ou escolas normais, elevadas ao nível superior e incorporadas às universidades. Os docentes formados por estas escolas teriam uma base de uma educação geral comum. ( p. 17)

A Constituição Federal, de 1934, vai permitir mudanças nesse quadro no âmbito introdução da gratuidade, obrigatoriedade do ensino primário em todo o país e da obrigação de recursos constitucionalmente vinculados para o financiamento da educação bem como da criação de Conselhos de Educação. Contudo, não houve alteração substancial na tradição de os Estados se responsabilizarem pela formação docente em Escolas Normais de nível secundário.

A lei n. 452, do governo Vargas, de 5 de julho de 1937, organizando a Universidade do Brasil, faz constar uma Faculdade Nacional de Educação. Essa faculdade, regulamentada pelo Decreto-Lei n. 1190, de 4 de abril de 1939, em pleno Estado Novo, dispõe como suas finalidades a de preparar trabalhadores intelectuais, realizar pesquisas e preparar candidatos ao magistério do ensino secundário e normal.

Essa Faculdade deveria contar com uma seção de Pedagogia constituída por um curso de pedagogia de três anos que forneceria o título de Bacharel em Pedagogia. Fazia parte também uma seção especial: o curso de didática de um ano e que, quando cursado por bacharéis, daria o título de licenciado. Esse é o famoso $3+1$ que, por longos anos, formou os licenciados para atuarem nos denominados ensino secundário (primeiro e segundo ciclos) ou ensino de $1^{\circ}$ grau (anos finais), ensino de $2^{\circ}$ grau e ensino fundamental (anos finais) e ensino médio.

Em 2 de janeiro, de 1946, já dentro de um espírito de redemocratização política do país, vem à luz a Lei Orgânica do Ensino Normal, Decreto - Lei n. 8.530, como ramo do ensino do segundo grau, a fim de prover a formação do pessoal docente necessário 
às escolas primárias. A lei regulamentava os currículos e outras exigências de caráter nacional. Ela previa, por exemplo, a existência de dois ciclos. O primeiro, de quatro anos, para formação de regentes, era dado pela escola normal regional. E o segundo ciclo, para professores primários, com três anos, seria dado na escola normal junto à qual haveria um grupo escolar.

A lei 4.024/61 não alterou significativamente a preparação de normalistas para o ensino primário face à lei orgânica de 1946. Essa lei dispunha que medidas de caráter geral deveriam ser normatizadas pelo Conselho Federal de Educação. Esse Conselho elaborou vários pareceres sobre a formação de professores, especialmente para os cursos superiores de licenciatura. Assim, o Parecer 251/62, do Cons. Valnir Chagas, introduz alterações curriculares no Curso de Pedagogia tendo sido homologado pelo então ministro da Educação Darcy Ribeiro. Nesse Parecer, o relator aponta a necessidade do professor primário vir a ser formado em ensino superior. O Parecer 292/62, do CFE também de mesma autoria regulamenta os cursos de licenciatura.

Antecedendo a própria reforma do ensino superior de 1968, o decreto-lei 53 de 1966 trazia, como novidade, a fragmentação das Faculdades de Filosofia, Ciências e Letras e a criação de uma unidade voltada para a formação de professores para o ensino de $2^{\circ}$ grau e de especialistas em educação - a Faculdade de Educação.

A Lei n. 5.540/68 impacta o curso de Pedagogia por meio do Parecer 252/69 de 11/4/69 de Valnir Chagas. Esse parecer institui no curso a parte comum necessária a todo e qualquer profissional da área e outra parte diversificada em função de habilitações específicas que também poderiam ser melhor trabalhadas na especialização, com exceção do Planejamento que seria uma habilitação própria do Mestrado. $\mathrm{Na}$ persistência de dúvidas sobre o curso de pedagogia, sua estrutura, organização e destino, o CFE, pela lavra de Cons. Newton Sucupira, dá origem ao Parecer n. 632/69. Nele, se busca compreender o conteúdo de uma Faculdade de Educação e que não se limita apenas ao curso de Pedagogia.

O Parecer 252/69 reconhecia a dificuldade técnica relativa a um pedagogo poder ser professor de ensino primário, sem uma adequada complementação metodológica. $O$ surgimento da Lei 5.692/71 deu ensejo ao Parecer 349/72 da Cons.a Terezinha Saraiva que versa sobre o exercício de magistério no primeiro grau pela habilitação profissionalizante específica de $2^{\circ} \mathrm{grau}$. Mas a relatora admite que a habilitação em grau superioréa desejável.

O final dos anos 1970 e a década de 1980, embora sem chegar a uma proposta concreta sobre o fazer pedagógico, ensejou muitas discussões, muitos encontros e congressos. Entre essas iniciativas, deve-se destacar a do governo federal em apoiar a melhoria da chamada habilitação de magistério por meio dos Centros Específicos de Formação e Aperfeiçoamento do Magistério - CEFAM - no nível de $2^{\circ}$ grau, que o MEC elaborou em 1982 e os estimulou, a partir de 1983, em parceria com as Secretaria de Educação. 
Os CEFAM nasceram como resposta às críticas feitas aos cursos de habilitação para o magistério na vigência da lei n. 5.692/71 e à queda de matrícula nesses cursos. Foi iniciativa do MEC, por meio das então SEPS/SDE/COES, que visava apoiar técnica, pedagógica e financeiramente os Estados que quisessem fortalecer estes cursos de modo qualitativo. Os CEFAM seriam em período integral, de duração de quatro anos com 44 horas semanais, cujos pretendentes deveriam passar por um processo seletivo. Um estágio vinculado fazia parte substancial do processo. Depois que a coordenação passou para as secretarias estaduais, até por conta da descontinuidade administrativa dos sucessivos governos federais, eles foram desaparecendo ${ }^{2}$. E o CFE, mediante o Parecer n. 161/86 assumia a necessidade de se rever o curso de Pedagogia.

Já entre as iniciativas ocorridas nesse período, a partir do movimento de educadores, destaca-se a criação do Comitê Pró-Formação do Educador em 1983 e a posterior criação da Associação Nacional pela Formação dos Profissionais da Educação - ANFOPE - em 1990.

Pesquisas se multiplicaram e publicações vieram à tona. Ao mesmo tempo, desafios novos e complexos postulavam novas investidas conceituais para categorizar novos fenômenos e novas práticas. Mas não houve uma definição formal sobre o assunto.

A nova LDB não resolveu o assunto de modo satisfatório. Continuam antigos problemas relacionados ao nível de formação, ao locus institucional, ao conjunto de componentes curriculares necessários e mesmo à questão federativa.

É verdade que iniciativas já foram tomadas como as Diretrizes Curriculares do Curso Normal Médio, pelo Parecer CEB 1/99 e pela Resolução CEB 2/99, as Diretrizes Curriculares Nacionais da Educação Infantil, pelo Parecer CEB 22/98 e pela Resolução CEB 1/99, as Diretrizes Curriculares do Ensino Fundamental, pelo Parecer CEB 4/98 e pela Resolução CEB 2/98, as Diretrizes Curriculares do Ensino Médio, pelo Parecer CEB 15/98 e pela Resolução 3/98, e as Diretrizes para os Institutos Superiores de Educação, pelo Parecer CP 115/99 e pela Resolução CP 1/99.

Outros instrumentos normativos mediaram a chegada desse programa federal de apoio à formação qualificada dos professores que atuaram na educação básica. Entre outros dispositivos, a LDB, de1996, que, além dos artigos próprios da formação de docentes, busca valorizar essa formação pela relação teoria/prática no inciso II, do art. 61, inclusive em estágio supervisionado. Diga-se que houve mudanças no art. 61 da LDB por meio da lei n. 12.014/09. Também o art. 62 sofreu importante alteração pela lei n. 12.506/09 ao implicar, explicitamente, no seu $\S 1^{\circ}$, a União na formação docente. Os estágios estão também estatuídos no art. 82, artigo alterado pela lei n. 11.788/08.

O Conselho Nacional de Educação, além dos pareceres e das resoluções supramencionados, continuou exercendo sua função normativa, ao elaborar os Pareceres CNE/CP n. 09/01, n. 27/01, n. 28/01 e as Resoluções CNE/CP 01/02 e CNE/ CP 02/02. 
Acrescente-se a lei n. 11.273/06, que autoriza a concessão de bolsas a participantes de programas de formação inicial e continuada de professores para a educação básica e o Decreto n. 6.755/09, que trata da Política Nacional de Formação de Profissionais do Magistério da Educação Básica.

3.

A redefinição do papel da CAPES, pela Lei n. 11.502/07 e regulada pelo Decreto n. 7.219/2010, no fundo, tem a ver com uma constatação e uma pergunta. A CAPES dirigiu um processo constatável e considerável de consolidação e valorização de pós-graduação nacional, cujo sucesso é inegável, sendo reconhecido no país e no exterior. Para tal sucesso, três fatores convergentes foram fundamentais: a qualidade e continuidade das ações, o financiamento e o incentivo das e nas ações avaliadas sistematicamente e a assunção pela comunidade científica das ações por meio de uma participação ativa e crítica. Mais do que um programa de governo, a CAPES do Ensino Superior/Pós-Graduação tornou-se política de Estado.

A pergunta é: por que não colocar essa sólida experiência, devidamente recontextualizada, a serviço da graduação naquele segmento que forma docentes, ou seja, licenciatura e pedagogia? Por que não podemos ter essa graduação à altura do que se conseguiu na pós-graduação? Por que não podemos ter licenciaturas e pedagogia tão boas quanto certos bacharelados?

O PIBID é um dos caminhos, entre outros, para se responder a esse desafio e que se insere dentro de ação financiada como incentivo para a qualidade. $O$ desafio é claro: essa ação prescinde ou carece dos outros dois fatores? Ou seja, continuidade qualificada pelo Estado Federal e adesão participativa e crítica pela comunidade da área?

Mas essas perguntas e essas respostas devem ser contextualizadas.

A situação do magistério, sua formação, sua carreira, seu exercício, é hoje um dos maiores problemas do país à vista do significado da educação para a cidadania e para a inserção profissional. As políticas públicas devem dar um encaminhamento consistente já que país não pode prescindir desse profissional. E as políticas públicas ainda não dispõem de respostas coordenadas e articuladas para sua valorização e necessita dessas respostas.

Dados do INEP/CAPES, analisando o campo das licenciaturas, trazem um retrato pouco animador da situação. Entre quadros, gráficos, apontamentos e análises, o relatório ${ }^{3}$ dessas agências do MEC diz: "sobram profissionais licenciados, mas faltam licenciados dispostos a exercer a profissão específica para a qual se formaram.". (p. 19)

Em outro trecho, diz o relatório:

${ }^{3}$ Relatório da Diretoria de Educação Básica/INEP: As licenciaturas e o Ensino Básico Brasileiros: diagnóstico Autoria de Dilvo Ristoff 2009. 
não obstante a constatação de que o número de profissionais licenciados é, em tese, e em todos os casos, exceto em Física e Química, suficiente para atender com folga à demanda estimada de professores do ensino básico, fica evidente que as licenciaturas padecem fortemente de dupla evasão: a evasão durante o curso e a evasão após o curso. (p.26)4.

Ao final, o relatório conclui:

Percebe-se, igualmente, em todas as regiões, que o número de licenciados atuantes no ensino básico é sempre muito inferior ao número de pessoas efetivamente licenciadas, não obstante a demanda por professores ser bastante superior. (...) Observa-se, portanto, que a falta de professores atuantes como um todo, não se deve à falta de oportunidade de trabalho, mas à falta de atratividade do trabalho no ensino básico. (p. 27).

A grande empregabilidade desse segmento de trabalho se perde devido à sua baixa atratividade.

Uma pesquisa levada adiante pelo Sindicato das Entidades Mantenedoras de Estabelecimentos de Ensino Superior de São Paulo - SEMESP -, de acordo com uma reportagem de O Estado de S. Paulo, de 03 de fevereiro de 2011, constatou que a taxa de evasão do profissional em Pedagogia é da ordem de 60\%. Segundo a mesma pesquisa, a disseminação de cursos de pedagogia a baixos custos atrai estudantes menos por "uma" opção profissional e mais para se "ter "diploma" de ensino superior.

Voltado para o interior das escolas formadoras, seus currículos e suas metodologia, sem deixar de lado aspectos relativos a carreira e salários, destaco dois textos recentes sobre o assunto. Trata-se do Relatório-texto das professoras pesquisadoras Bernardette Gatti e Marina Munis Rossa Nunes ${ }^{5}$, e um livro de Bernardette Gatti e Elba Barreto ${ }^{6}$ cujos resultados advindos de pesquisas não são nada animadores. Se os profissionais do ensino são o terceiro grupo ocupacional mais numeroso do país, se o poder público emprega $83 \%$ deles, se eles são predominantemente do sexo feminino, se os salários de 50,4\% deles oscila, diferenciadamente, entre 3 a 10 salários, não admira que apareça na pesquisa uma reduzida disponibilidade deles para os estudos (após a formação inicial), são leitores de poucos livros e jornais e aparece pouco acesso a outros insumos culturais. ${ }^{7}$

As pesquisas constataram um crescimento bastante grande no âmbito da oferta desses cursos por meio da educação a Distância e, identificada certa improvisação na montagem dos mesmos, também se averiguou uma baixa capacidade da União para o acompanhamento e supervisão da EAD em todo o país.

Mais do que isso, as pesquisas constataram a ausência de um perfil formativo mais definido do vir-a-ser professor, sendo que isso se reflete nos currículos e nos estágios. Os currículos são predominantemente fragmentários e dispersos em que há um grande distanciamento entre conteúdos teóricos e dimensões práticas. Os estágios aparecem sem um planejamento e sem uma articulação com os estabelecimentos dos sistemas de ensino. Segundo o depoimento de muitos sujeitos das pesquisas, boa

${ }^{5}$ Trata-se de um Texto Relatório da Fundação Carlos Chagas organizado pelas autoras supra citadas sob o título Formação de professores para o ensino fundamental: estudo de currículos das licenciaturas em pedagogia, língua portuguesa, matemática e ciências biológicas. Vol. 29, março de 2009.

${ }^{6}$ Trata-se do livro Professores no Brasil: impasses e desafios. Brasília UNESCO, 2009

7 Cf. VIEIRA, Juçara Dutra. Identidade expropriada: retrato do educador brasileiro. Brasilia: CNTE, 2003 e também UNESCO. 0 perfil dos professores brasileiros: o que fazem, o que pensam, o que almejam. São Paulo: Moderna, 2004. 
parte dos cursos é dada por meio de apostilas, resumos e cópias de trechos de livros.

Afora os salários pouco competitivos, constatou-se que os planos de carreira em outras profissões e carreiras são mais atrativos.

Radiografia semelhante também povoa as reportagens de jornais e revistas. Eles, em base a outras agências de pesquisa, inclusive oficiais como o próprio MEC (Censo da Educação Superior, 2005-2009), IBGE e o IPEA, apresentam abertamente a desvalorização do magistério como é o caso da queda do número de formandos em cursos de pedagogia, normal superior e licenciaturas. Como causas, apontam-se o aviltamento dos salários e a ausência de planos estimulantes de carreira. Um novo complicador nasce dos riscos cada vez mais evidentes das várias formas de violência no entorno da escola, no ambiente escolar e até mesmo na sala de aula. Além disso, as já condições precárias de trabalho se avolumam em bairros pobres e de periferia.

Outras pesquisas apontam a baixa procura por esses cursos, traduzindo uma real fuga do magistério e uma sedução por outros caminhos de inserção profissional.

Alguns sistemas acabam aceitando como professores um pessoal não diplomado adequadamente até porque os diplomados terminam por buscar outras opções de mercado mais convidativas.

4.

Não por acaso, sabendo a importância da educação para o presente e para o futuro, a presidente da República enfatizou, em seu discurso de posse, que daria especial atenção à recuperação da "autoridade pedagógica" do professor. A autoridade pedagógica não se adquire por meio do voluntariado ou diletantismo. Só mediante uma formação sólida é que ela se torna real. A mesma presidente, em pronunciamento à nação, em fevereiro de 2011, reafirmou o compromisso com a "melhoria da educação" e a luta por uma "educação de qualidade". Disse ela na oportunidade:

Nenhuma área pode unir melhor a sociedade que a Educação. Nenhuma ferramenta é mais decisiva do que ela para superarmos a pobreza e a miséria. Nenhum espaço pode realizar melhor o presente e projetar com mais esperança o futuro (...) É hora de investir ainda mais na formação e remuneração de professores (...) acabar com essa trágica ilusão de ver aluno passar de ano sem aprender quase nada. (Brasil, 2011)

Ainda que abaixo do que seria necessário, a lei do piso deu um passo importante para se começar a recuperar o salário inicial do professor. Foi uma conquista porque, apesar de outras leis em outros tempos, tal passo, ainda que exigido nacionalmente, ficava por conta da autonomia dos Estados e Municípios. Com essa lei, a obrigatoriedade do piso é nacional, aliás dispositivo reconfirmado pelo Supremo Tribunal Federal. Outro passo fundamental é a existência de uma carreira que dê expectativas de reconhecimento quando o professor se qualifica em nível pós-graduado ou sob formas pertinentes de formação continuada e de avaliação. E esse passo só se dará quando 
a formação inicial do docente estiver calcada em bases teóricas sólidas e em práticas previamente aprendidas nessa formação.

Eis porque se pode apontar, no projeto de PNE (8.035/10), as metas de 15 a 18 como promissoras. Citem-se 3 estratégias de acordo com a meta 15:

15.3- Ampliar programa permanente de iniciação à docência a estudantes matriculados em cursos de licenciatura, a fim de incentivar a formação de profissionais do magistério para atuar na educação básica pública. (grifo adicionado).

15.5- Institucionalizar, no prazo de um ano de vigência do PNE 2011/2020, política nacional de formação e valorização dos profissionais da educação, de forma a ampliar as possibilidades de formação em serviço.

15.9- Valorizar o estágio nos cursos de licenciatura, visando trabalho sistemático de conexão entre a formação acadêmica dos graduandos e as demandas da rede pública de educação básica.

É nesse contexto que se insere o PIBID. De um papel historicamente recuado do MEC a um papel mais proativo face aos gritantes e severos problemas da educação escolar, esse Ministério clamou pela experiência da CAPES, a fim de que a União pudesse oferecer algo para superar tais limites.

Um primeiro passo foi o Decreto n. 6.755/2009 que trata da Política Nacional de Formação de Profissionais do Magistério da Educação Básica mais o Decreto n. 7.415/2010 que retoma o decreto anterior e o amplia também para os funcionários que atuam nas escolas da Educação Básica.

E a outra medida é o próprio PIBID que valorizará a excelência dos projetos pedagógicos que façam a articulação entre a instituição formadora, os sistemas de educação e os estabelecimentos de ensino. Valorização que se faz acompanhar de 5 modalidades de bolsas de estudos e pesquisa envolvendo os profissionais dessa triangulação. Mas isso não se faz sem planejamento articulado com os sistemas de ensino e os respectivos estabelecimentos e também não se concretiza sem uma articulação fecunda de ida/ volta entre o estabelecimento em que estará o estagiário e a instituição formadora.

Trata-se, pois, de um investimento de médio e longo prazo, no aspecto crucial da formação inicial em geral (projeto pedagógico de qualidade) e em especial no que se refere à relação teoria e prática. Lembre-se que a consolidação da Capes na pósgraduação não se fez de modo imediato.

5.

Ser professor é algo que o estudante deve ir se fazendo, tornando essa trajetória cada vez mais objeto de uma opção profissional consciente e crítica, respaldada em um compromisso político democrático e em uma competência profissional qualificada. Oprofessor nem é e nem não é. O professor devém.

Nasce daí a orientação metodológica fundante dos Pareceres do CNE: todas as 
atividades concernentes a essa formação profissional devem estar bafejadas pela relação teoria/prática, prática/teoria. Não apenas os momentos que a lei impõe como práticas devem ser iluminados por essa relação, como também os momentos voltados para os aspectos cognitivos.

Ao mesmo tempo, essa relação teoria/prática conhece como método processual a compreensão descritiva, analítica e problematizadora das atividades implícitas em todos os componentes curriculares como uma circularidade de caráter elíptico e interativo da ação/reflexão/ação.

Esses princípios metodológicos que devem se fazer presentes em todas as atividades são a base do projeto pedagógico das instituições cuja autonomia é garantida por lei.

O momento do saber não está separado do fazer e vice-versa, mas cada qual guarda sua própria dimensão epistemológica.

O momento do saber, então, resguarda o aprender a ser professor como um saber profissional. Como diz o próprio Parecer CNE/CP n. 28/02:

O ser professor não se realiza espontaneamente. Na formação do ser professor, é imprescindível um saber profissional, crítico e competente e que se vale de conhecimentos e de experiências. O projeto pedagógico reúne em si, como componentes curriculares, tanto o que se refere aos conteúdos próprios de uma área do conhecimento (saber científico), quanto o que se destina à apropriação de conteúdos próprios do saber científico-pedagógico.

O momento do fazer também abriga em si o aprender a ser professor como um saber profissional intencionado a uma ação docente nos sistemas de ensino.

Mas tais momentos do saber - fazer e do fazer - saber docentes, parafraseando Kant, não são ocos (pelo confinamento da prática aos seus aspectos empíricos) e nem cegos (pelo confinamento da teoria em si própria).

Momentos dessa relação teoria/prática, articulados no conjunto do projeto pedagógico podem (e devem) ser desenvolvidos junto com qualquer outro componente curricular intra ou extramuros universitários da formação docente.

Entre outros objetivos, pode-se dizer que o PIBID pretende ofer ecer ao futuro licenciado um conhecimento do real em situação de trabalho, isto é, diretamente em unidades escolares dos sistemas de ensino. É também um momento para se refletir analítica e criticamente sobre esse real e provar (em si e no outro) a realização dos saberes e das competências exigidas na prática profissional e exigíveis dos formandos, especialmente quanto à regência. Mas é também um momento para se acompanhar alguns aspectos da vida escolar que não acontecem de forma igualmente distribuída pelo semestre, concentrando-se mais em alguns aspectos que importa vivenciar. É o caso, por exemplo, da elaboração do projeto pedagógico, da matrícula, da organização das turmas e do tempo e espaço escolares. Aqui não se pode deixar de se referir a 
um modo de ser desafiante, enriquecedor e apaixonante do extramuros: trata-se da desterritorialização da sala de aula por meio do conhecimento da realidade onde se situa o estabelecimento e seu entorno, as visitas às famílias e aos Conselhos Setoriais.

Outra via importante é aquela on-line das tecnologias da informação e do conhecimento pela rede mundial dos computadores.

É no sentido de uma formação holística que o conceito de competência deve ser inserido e entendido. Que de pior para um profissional do que ser visto e reconhecido como alguém em quem se verifica a ausência de conhecimentos e aptidões necessários para o exercício de um trabalho ou para o julgamento de alguma coisa, ou seja, um incompetente? Ser chamado de competente, por outro lado, é ser reconhecido como um profissional capaz, crítico e consciente, positivamente avaliado porque se trata de alguém que, reunindo em si a relação teoria/prática, torna-se capaz de dar uma resposta consequente a problemas complexos das finalidades maiores das funções da escolaridade e aos problemas da vida social contemporânea.

O docente competente é, pois, aquele que sabe, que sabe fazer, que sabe fazer bem e que sabe fazer sabendo e fazendo o porquê e o para quê das coisas relativas à sua profissão, já que dele se postula o princípio metodológico da teoria/prática e da ação - reflexão - ação.

Esse escopo do PIBID é o que a educação jesuítica denominava de tirocínio. Tirocínio vem do latim, de um lado de tiro/onis e significa recruta, soldado recém alistado (daí a expressão "tiro de guerra"), aprendiz, novato e, de outro lado, provém de cinium (que por sua vez vem de canere = cantar). Assim, tirocínio era a trombeta (sineta/campainha) que tocava (cantava), de manhã, a fim de acordar os recrutas para os exercícios que fariam dele um soldado. Trata-se, pois, de um tempo de aprender em serviço, de familiarizar-se sob controle e orientação de alguém mais experiente e competente. É o learning by doing pelo qual se conjuga teoria/prática. Será aquele período transitório de formação e aprendizagem que, através de um tempo de permanência no estabelecimento sob orientação de uma figura sênior, se torna uma condição da classe inicial de uma carreira.

Nesse sentido, é altamente recomendável que o estágio, de modo similar ao que ocorre no internato da área da saúde, seja, a partir do meio para o final do curso, um momento de coroamento formativo em que a relação teoria/prática já seja um ato educativo em ação. É na imersão no real em que vai trabalhar, que o futuro professor e, em processo de sê-lo, deve ter conhecimentos sobre o sentido e o significado do ambiente escolar em suas mais diferentes facetas e contextos.

O Pibid, ao investir na formação de futuros docentes, ainda que não de todos os formandos das licenciaturas e da pedagogia, busca um caminho de dignificação do status do magistério. As escolas só hão de realizar seus fins quando elas forem povoado de bons docentes. O Pibid faz parte efetiva, ainda que limitada, de um esforço da União em prol da dignificação do magistério dentro do processo formativo inicial. 
Seus resultados mais claros - é bom que se diga -, tais como os que aconteceram com a Capes na pós-graduação, são produtos de média e de longa duração e de outras iniciativas que sejam produto de uma política de Estado da qual decorram ações continuadas, conscientes e avaliadas. E eles só se tornarão uma cultura de formação caso haja um idêntico esforço da parte dos outros entes federativos.

6.

O que está em jogo é o direito de aprender que é propriamente o direito à educação que se liga intrinsecamente à função pública do Estado na medida em que só ele pode estender universalmente a escola para todos e assim atender o conjunto dos cidadãos, com imparcialidade de modo a fazer cumprir os grandes objetivos da democracia e da justiça. Daí as obrigações do Estado quanto ao apoio, qualificação e financiamento desse direito.

A Constituição da República, de 1988, reconheceu o direito à educação como o primeiro dos direitos sociais (art. $6^{\circ}$ ) assim como um direito do cidadão e dever do Estado (art. 205). E, por essa razão, estabeleceu princípios, diretrizes, regras, recursos vinculados e planos de modo a dar substância a esse direito. Ao explicitar esse direito, elencou sob a forma de assinalação de formas de realizá-lo tais como gratuidade e obrigatoriedade com qualidade e com proteção legal, ampliada e com instrumentos jurídicos postos à disposição dos cidadãos. Assim, cria prerrogativas próprias para as pessoas em virtude das quais elas passam a usufruir de ou exigir algo que thes pertence como tal. Do dever, nascem obrigações que devem respeitadas, tanto da parte de quem tem a responsabilidade de efetivar o direito, como o Estado e seus representantes, quanto da parte de outros sujeitos implicados nessas obrigações. Do direito nascem as exigências de cobrar uma efetivação de qualidade.

Essa ação da CAPES/MEC - PIBID - é um dos mobilizadores em vista desses pressupostos cujo objetivo é uma ação pedagógica compromissada com a democracia, com o papel social da escola, com a ciência e certamente com a busca cada vez mais dignificante desse profissional, que é o formador básico de todos os outros profissionais.

\begin{abstract}
The Scholarship Program Initiation in Teaching - PIBID - the object of this study, aims at assembly this legislation that gives consistency within the powers of the Union under the collaboration with the federal entities, a way of valuing the teaching of basic education. A $d$ such valuation occurs at the time of the undergraduate students and pedagogy are having their initial training in higher education. The study, after a brief historical retrospective on teacher training in Brazil, shows how the successful experience of the Coordination Staff Support of Higher Education-CAPES - under graduate, tends to berecontextualized in undergraduate courses and pedagogy. The PIBID seeks to offer the future licensee knowledge of the real work situation directly in units of school education
\end{abstract}


Programa institucional de bolsa de iniciação à docência da Capes e a formação docente

systems. Therefore, with the support of institutional training entity, through an supervisor and the reception in the establishment of basic education by a senior professor in the exercise of teaching. Their results are more consistent products of medium and long term and other initiatives that are the product of a state policy which elapse continuing actions, conscious and evaluated.

Keywords: Teaching formation and initial training. Teaching formation and education systems. Support programs and teaching formation.

\section{Referências}

BRASIL. Ministério da Educação e Cultura. Secretaria de Educação Superior. Reformulação dos cursos de preparação de recursos humanos para a educação (coletânea), 1982.

BRASIL. Pronunciamento à nação da Presidenta da República, Dilma Rousseff, em cadeia nacional de rádio e TV - Brasília/DF - 2011. Disponível em: < http://www2.planalto.gov. br/imprensa/discursos/pronunciamento-a-nacao-da-presidenta-da-republica-dilmarousseff-em-cadeia-nacional-de-radio-e-tv >. Acesso em: 20 fev. 2013.

ENCONTRO NACIONAL. Reformulação dos cursos de preparação de recursos humanos para a educação (documento final, Belo Horizonte, 1983). Cadernos Cedes. São Paulo. n 17, p. 58-65, set. 1986.

BRZEZINSKI, Iria. A formação do professor para o início da escolarização. Goiânia: UCG, 1987.

BRZEZINSKI, Iria. Pedagogia, Pedagogos e Formação de Professores. Campinas: Papirus, 1996

BRZEZINSKI, Iria. Trajetória do movimento para as reformulações dos cursos de formação de profissionais da educação. Em Aberto. 54: (12) Brasília: INEP, 1992.

CURY, Carlos Roberto Jamil. A Educação na Revisão Constitucional de 1925-1926. Bragança Paulista: EDUSF, 2003.

NAGLE, Jorge. Educação e Sociedade na Primeira República. São Paulo: EPU/EDUSP, 1974.

MANIFESTO dos pioneiros da educação nova (1932) e dos educadores (1959). Recife: Fundação Joaquim Nabuco: Ed. Massangana, 2010. 125 p. (Coleção educadores MEC) 
Revista HISTEDBR On-line. O MANIFESTO DOS PIONEIROS DA EDUCAÇÃO NOVA (1932). Disponível em: <http://www.histedbr.fae.unicamp.br/revista/edicoes/22e/ doc1_22e.pdf> Acesso em: 24 abr. 2013 